\title{
Puno y Encinas, entre la rebelión campesina y la educación (1895-1910) ${ }^{1}$
}

Apuntes de Investigación

Recibido: 28/08/2020

Aprobado: 04/11/2020

Publicado: 05/02/2021
Iván Isaac Caldas Figuerola

Universidad Nacional Mayor de San Marcos

ivacafi@hotmail.com

\section{RESUMEN}

Puno, una región de fuerte régimen servil y de monopolio católico a finales del siglo XIX y principios del XX, vivía un clima social lleno de convulsiones y muerte; rebeliones campesinas contra el gamonalismo. En este escenario nace una escuela cuya intención era generar un proceso de inclusión del niño indígena para convertirlo en un ciudadano sujeto de derecho. Este trabajo propone que un joven partícipe de aquellos acontecimientos, José Antonio Encinas, practicó el enfoque antropológico, se anticipó a las escuelas populares Manuel Gonzales Prada y forjó allí un laboratorio pedagógico, laico, rico en valores ciudadanos, aprendiendo de las escuelas de los adventistas, del indigenismo temprano y de la Escuela Nueva.

Palabras Clave: Encinas; indigenismo temprano; Escuela Nueva; adventistas; Puno.

\section{Puno and Encinas, among peasant rebellions and education (1895-1910)}

\begin{abstract}
Puno, a region of strong regime subservient and monopoly Catholic in late 19th century and early 20th, lived a social climate that is filled with convulsions and death; peasant rebellions against the gamonalismo. In this scenario was born a school whose intention was to generate a process of inclusion of the indigenous child to become a citizen subject of law. This paper proposes that a young participant in those events, José Antonio Encinas, practiced the anthropological approach, Manuel Gonzales Prada was anticipated to popular schools and there forged a laboratory teaching, secular, rich in values citizens, assimilating Adventist school, early indigenism and the New School.
\end{abstract}

KeYwords: Encinas; early indigenism; New School; adventism; Puno.

1 Este texto es un resumen de la tesis «Proyecto Educativo de José Antonio Encinas» (2018) sustentada en la UNMSM para optar el grado de Magister en Historia. 


\section{Introducción}

$\mathbf{U}$ no de los maestros peruanos más reconocidos en el Perú es José Antonio Encinas, un puneño que vivió entre 1886 y 1958. Sin embargo, su aporte a la pedagogía y a la política no está puesto en práctica de forma generalizada en la vida nacional; «a pesar del tiempo transcurrido muchos de los planteamientos de Encinas siguen aún vigentes» (López Martínez, 1973: 24). Su desempeńo teórico y pedagógico, salvo excepcionales colegios alternativos de Lima, no ha sido carta geográfica en las políticas educacionales como muchos quisieran.

El trabajo de Encinas en el mundo educativo ha sido muy amplio, encontramos que su vida y producción académica es muy extensa. "Es decir, su actuación pública discurrió por los distintos estamentos de la docencia» (Gonzales, 2013: 13). Aunque educado en el Perú y en universidades europeas, director del legendario Centro Escolar 881 en Puno, parlamentario durante varios períodos y rector de la Universidad Nacional Mayor de San Marcos, mucho de su trabajo profesional esta aún desperdigado en el mundo, pues vivió y trabajó en Guatemala, Inglaterra, España, Cuba; esa rica experiencia en aquellos países no ha sido recogida, menos estudiada.

Este ensayo presenta una propuesta que tiene como eje principal la formación política y social de los pedagogos provincianos y, especialmente, la del maestro Encinas. El tres veces rector de la Decana de América, Luis Alberto Sánchez dijo de él: «uno de los hombres más puros de nuestra historia republicana y uno de los maestros menos discutidos de nuestra historia cultural» (En Pareja Paz Soldán, 1978: 19). Este artículo pretende dar un aporte a la historia de la educación ya que toma como nervio central las vivencias juveniles y la construcción de las ideas de Encinas. Es una línea de investigación cuyas preguntas a resolver son ¿Cuáles fueron las conexiones del joven Encinas en la sociedad de Puno? ¿Cuánto y cómo marcaron su vida el contexto violento y conflictivo de las rebeliones campesinas de su región? ¿Cómo lo influyeron? ¿Qué visión se gestó en el adolescente Encinas ante el pesar y los sueños de cambio social? ¿Cómo influyó en este puneño, la campaña educativa de los grupos adventistas que se instalaron en Puno? ¿Qué buscó forjar, en el campesinado, con un proyecto educativo?
Asimismo, las discusiones y acciones de un indigenismo temprano, de fines del siglo XIX e inicios del XX, deben haber dejado huella en el joven Encinas, pues el escenario y la época estaban cargados de acontecimientos muy importantes. El objetivo de este trabajo es identificar los elementos de conexión entre la experiencia juvenil de Encinas con las rebeliones campesinas de principios del siglo XX y establecer la influencia que generó en su proyecto educativo. Colaborar, así, con una historia de la educación rural y regional, que nos advierta de los beneficios de una modernidad en el aula, pero que resulta amenazada por las gavillas del burocratismo local y nacional; que nos anticipe de los obstáculos humanos y materiales que hay que sortear para llevar a cabo una política educativa moderna.

Mucho se discute en la actualidad sobre la necesidad de una educación que ayude a la convivencia armónica en la sociedad peruana, «mientras más intolerantes somos, menos derechos se reconocen» (Giusti, 2015: 1). Dentro de ese camino las implicancias son grandes y germinales, las ventajas de una educación en libertad, formación de ciudadanía y de derechos entre los niños, es fruto maduro de jugosa savia que resulta ajena para gran parte de la sociedad andina. El proyecto educativo enciniano, tiene un contenido laico, democrático, laborista y nada libresco, una apertura al trabajo docente sin dogmas ni imposiciones, nada que atormente a los estudiantes.

\section{Puno en la post guerra del salitre}

Nuestro primer contacto con el maestro Encinas proviene de los estudios pedagógicos y reseńas de temas educativos, textos de historia de la educación que solamente resumen sus recomendaciones pedagógicas en el trabajo docente. Más adelante, nos embarcamos en una tesis de maestría que se orientó a buscar las fuentes intelectuales e históricas que gestaron la construcción de su moderno proyecto educativo. En este camino de investigación por fuentes primarias, textos y archivos, en la lectura de las tesis, artículos, diarios y revistas de la época, el entusiasmo se acrecentó, pues de aquella hermenéutica emergió una generación de maestros regionales y altiplánicos, poco divulgada. En ese período destacaron artistas, pensadores y 
políticos que se comprometieron con la defensa de los campesinos, actuaron en hechos políticos, debatieron con ideas renovadoras, lucharon por renovar la mentalidad de los lugareńos; todo un momento interesante para la historia regional e intelectual del mundo andino.

Fue en Puno y el sur andino, donde estallaron las rebeliones campesinas más continuas y sangrientas «furiosas rebeliones, solo en Chucuito se sucedieron las de 1903, 1905 y 1912...» (Basadre, 2005: 240). Las comunidades campesinas, dedicadas al pastoreo de camélidos andinos, se entusiasmaban con el trabajo de crianza de ganado y con la textilería pero enfrentaban el apetito de los grandes comerciantes, quienes los acosaban usando a los rescatistas, unos intermediarios del comercio lanar que más parecían asaltantes (Jacobsen, 2013; Stern, 1990; Burga y Reátegui, 1981; Burga y Flores Galindo 1979). Fue en Puno, también, donde el indigenismo se hizo carne tempranamente; así lo reconoce el maestro de la etnohistoria Luis Valcárcel (1980), aquel que esperaba a un Lenin andino.

Perú ingresaba al tiempo de una sociedad definida por un Estado oligárquico, marcadamente desigualitaria. Por otro lado, los trabajadores de entonces, campesinos, jornaleros y también los comuneros vivían en un círculo de latifundismo y poder terrateniente en las haciendas. Muchos hacendados hacían endeudar a los campesinos y les despojaban las tierras, "hallé 165 casos en los cuales éstas fueron vendidas explícitamente como pago a una deuda» (Jacobsen, 2013: 366). Hacían contratos improvisados, adulterando los términos, aprovechando el analfabetismo de los indígenas.

Ciertos capataces y propietarios acosaban a los yanaconas, arrendires y allegados (denominaciones asignadas a los campesinos, diferenciados por un régimen jerárquico de servidumbre) para usurpar más tierras y ganado. Incluso se aprovechaban del trabajo gratuito de campesinos, el sistema yunasi (Jacobsen, 2013). Los japoneses llegaban en 1899 para cubrir a los chinos coolíes antiguos, los enclaves se instalaban por todo el territorio y los hacendados formaban una dupla con grandes capitales foráneos en medio de un poder excluyente y poco democrático.

En la mayoría de textos que analizan a Encinas, encontramos sus propuestas pedagógicas, pero no sus influencias previas. Comentan su didáctica de aula, pero no mencionan sus primeros pasos en la lucha política; cuentan que renovó las técnicas de alfabetización, que incentivó el trabajo práctico de la educación naturalista, que concibió a la asignatura de la historia como un programa político, que enfatizaba la sicología propia del niño andino (Sánchez, 2004; Barboza, 2007; Portugal, 2015; Marrou, 2012). Conocemos su poder en las aulas de San Marcos como rector reformista: que implementó los Colegios universitarios, fusionó las Facultades de Letras y Ciencias, que creó la sección preparatoria, incentivó la investigación y que instituyó los estudios de posgrado (Escarrachi, 1966). Que en San Marcos cambió los exámenes finales por trabajos académicos y periodísticos, organizó la extensión universitaria, para llegar a los trabajadores y a la clase media; que favoreció a los estudiantes con el sistema selectivo de cursos y permitió su intervención en el cogobierno universitario (Gonzales, 2013). Falta estudiar, sin embargo, un pasaje importante de su vida, no sabemos quiénes eran sus héroes cuando, adolescente, crecía en el altiplano, rodeado de quechuas y aimaras, en un marco de gamonalismo y alzamientos campesinos, escuchando a los intelectuales liberales, viendo a curas peleándose con evangélicos.

No se ha investigado cómo se fue construyendo en su juventud, una emoción social, categoría teórica que él empleaba para calificar el sentimiento $y$ activismo que desarrolla una vanguardia intelectual en su camino socio-político (Encinas,1958). Esa pasión que siente un actor y líder que apunta, dentro de un movimiento de consciencia política, a un proyecto renovador de su sociedad.

Es muy importante conocer los pormenores de las actividades de los provincianos pioneros del indigenismo y los efectos de la rebelión en Juliaca y Pomata, entre otras más. Así, también, es importante estudiar la campańa evangelizadora de las iglesias adventistas que se instalaron en la zona, cómo se desenvolvieron y qué reacciones tuvieron, ante esto, los curas católicos. Asimismo, reconocer las pioneras experiencias de escuelas rurales a cargo de algunos hijos de Puno, como la escuela de Utawilaya, una pequeña casita que contaba con un sincero y profundo toque rural e indigenista. Esto es, mi hipótesis se orienta a que las intensas rebeliones campesinas por la tierra, las escuelas de los adventistas y el movimiento indigenista de Puno impactó de gran manera en 
el joven Encinas, tanto que le hizo construir un proyecto de transformación educativa y social, usando la doctrina pedagógica como herramienta para transformar la vida, la economía, la política y el pensamiento de los habitantes rurales de Puno y del mundo andino. Una escuela para enfrentar la vida desde el frígido y recio altiplano.

$\mathrm{He}$ recurrido a fuentes primarias sobre el tema respectivo. Me refiero a manuscritos de las autoridades de la época, de prefectos y subprefectos; los testimonios de los testigos de la zona y de la época han sido fundamentales, tomando en cuenta que existen muchos pensadores liberales de Puno que fueron pieza clave en los años previos a la aparición del joven maestro Encinas. Tenemos a Juan Bustamante, Mariano H. Cornejo, Federico More. Algunos documentos del clero de Puno son importantes para reconocer el ideario y pensamiento político religioso conservador que imperaba entonces, hasta que fue enfrentado por nuevas corrientes librepensadoras.

Igualmente existen trabajos que estudian al sur andino en el área escolar. En el Perú, luego de la guerra del salitre, los medios oficiales y escolares se tiñeron de un agresivo movimiento anti-chileno y de un "discurso chauvinista» (Espinoza, 2007: 31), dentro de un crudo control católico conservador y gobiernos que temían asumir cambios de apertura social. Ese sentimiento anti-chileno se ha mantenido por muchas décadas, la militarización de la escuela peruana y los gobiernos militaristas han vivido de ese ánimo. En Bolivia pasó algo distinto. Una guerra civil, entre liberales y conservadores (1898-1899), da como resultado un gobierno liberal, a cargo de José Manuel Pando. Éste impone la educación unificadora (Martínez, 1998), buscando uniformizar las tradiciones y culturas en una nación con aires de pedagogía europea; para esto, llamaron a pedagogos chilenos para modernizarse y favorecer las reformas. Los liberales bolivianos polemizaron con la iglesia católica, ya que el poder religioso rechazaba un Estado liberal y se consideraba el baluarte de la acción educativa.

En Argentina la corriente pedagógica Escuela Nueva asomaba con intensidad. Crearon una facultad de ciencias pedagógicas con el enfoque positivista, racionalista y laborista, que dicha corriente postulaba. Ejercieron en sus aulas una vida académica sin autoritarismo, ni castigos físicos; funcionaba una escuela mixta desde 1887 en Buenos Aires. Los vientos no solamente eran alisios, desde el sur-este hacia el Perú, también eran ideas renovadoras que soplaban, de seguro, hacia el mundo altiplánico de Bolivia y de Puno a inicios del siglo XX. Vientos e ideas que refrescaron a muchos puneños, pues era muy común que sean alcanzados por la prensa, las ideas anarquistas, los nuevos estilos estéticos que soplaban en el sur andino.

\section{Tempestad en el Altiplano}

La región altiplánica estuvo fuertemente convulsionada a fines del siglo XIX y a inicios del XX. Los problemas sociales eran diversos y continuos, las rebeliones de los campesinos contra el despojo de tierras y frente a la carga de explotación laboral que sufrían por la servidumbre señorial, a cargo del gamonalismo, resultó una bomba de tiempo que derivó en una gama de movimientos sociales en varios aspectos. Los prefectos y sub-prefectos denunciaban "...intolerables abusos de los empleados de la Peruvian Corporation" (BN, 1900: 8), se apenaban de la conducta de los párrocos por los escándalos que protagonizaban con sus convivientes y le pedían a su superior "arme un número de veinte ciudadanos» (BN, 1896:2) para frenar la rebelión ya que los indígenas se organizaban para enfrentar el impuesto a la sal -uno de tantos abusos fiscales- y para luchar contra los curas, jueces y prefectos.

Muchos pueblos, caseríos, localidades como Pomata, Juliaca y Platería eran lugares de alto poder de movilización social. Los prefectos y sub-prefectos pedían ayuda al gobierno central y a otras regiones cercanas para reprimir la rebelión campesina que, secularmente, rechazaba la servidumbre del trabajo de yanaconaje, que se hartaba de las artimañas de los jueces y de los gendarmes. Un puneño viajero e ilustrado, Juan Bustamante, dejó bien en claro su malestar: "confieso francamente que la espada no ha hecho, ni con muchos, tantos males al Perú como los que están causando el clero y el foro...» (Bustamante, 1959:62); parlamentario, prefecto y escritor organizó en 1867 una agrupación pionera del indigenismo, $\mathrm{La}$ Sociedad Amiga de los indios y, por si fuera poco, gestó una insurrección, identificándose con el apelativo de Túpac Amaru III. 
Muchos documentos oficiales grafican este malestar antigamonal y anticlerical, las autoridades locales se quejaban de los curas acusándolos de «... fanatizadores de la raza indígena, la explotan a su manera...convirtiendo las fiestas en verdaderas saturnales en las que se rinde más culto a Venus y Baco, que al santo Patrón de la Doctrina» (BN, 1899: 17-18). Las fiestas religiosas habían derivado en licor y gastos que empobrecían más a los indígenas.

Los prefectos experimentaron tremendo miedo a los alzamientos, tanto o más que los señores terratenientes, "las familias se refugiaron en el templo porque temían que los indígenas de sus ayllus...invadieran y ejercitaran los actos de barbarie que otras veces practicaron...»(BN, 1896:1). Demostraron, además, una visión prejuiciosa, casi escolástica, pues veían al indio solamente como un ser lleno de atavismo y nada cercano a las labores creativas del arte, ni a la escolaridad profesional. El propio ministro de Justicia, Culto e Instrucción pública de esa época, Jorge Polar, reconocía las limitaciones del sector para cumplir con las metas de integración nacional; informó que debería haber cinco mil escuelas, pero no llegaban a dos mil; que debían contar con ocho mil maestros y solo tenían dos mil (El Peruano, 1903).

Es justo reconocer los debates dentro del Partido Civil, que gobernaba entonces, sobre la necesidad de una educación rural, de carácter indígena, de modernizar el contenido y objetivo de la educación nacional; era visible la influencia del positivismo y la sociología (Ccahuana, 2013). Los civilistas de renombre encendían el clima académico con sus planteamientos: Villarán postulaba una educación liberal, en procura de profesiones para el trabajo industrial, mientras que Alejandro Deustua preconizaba una educación elitista, solo para algunos privilegiados, despotricando de la población andina, "la degeneración del indígena no estaba determinada por su raza, sino por su misma condición social» (Ccahuana 2011: 18). Sin embargo, las reformas de la administración de Pardo y Barreda (1904-1908), contenían un lamentable trasfondo; insistían en el aspecto racial, en la exclusión. Es decir, los contenidos educativos irían de la mano de una visión desigualitaria y excluyente contra la población indígena.

A inicios del siglo XX, el gobierno de López de Romaña había diseñado un nuevo Plan de Estudios para el primer grado de la primera enseñanza, elaborado por una comisión especial en 1902. Es evidente, el poco cuidado de la campaña educativa peruana de aquella época, a diferencia de Bolivia, donde el propio gobierno refrendaba los cambios socio-educativos en la vida nacional. Lo notamos al revisar los cursos que asignaba ese plan de López: «en lenguaje, palabras fáciles; en historia del Perú, narraciones verbales pintorescas sobre los hechos más importantes hasta la caída de los Incas; en educación moral, doctrina cristiana y oraciones principales de la misa» (El Peruano,1902: 7 de julio, p. 42). Al parecer, muchos puneños no tomaron esas asignaturas como importantes para el desarrollo de la infancia en su región y buscaron una renovación de la escuela.

El comercio de lanas creció bastante en el sur, pero no se implementaba una política ganadera de innovación en la crianza. Los comuneros preferían realizar el comercio directamente, sin embargo, grandes hacendados arremetían contra los campesinos. Entre unos y otros, estaban unos sombríos intermediarios (rescatistas y alcanzadores), agentes de presión, casi delincuentes, coludidos con jueces que acomodaban la ley para sus beneficios particulares, una muestra de la ilegalidad y del atropello contra los campesinos (Jacobsen, 2013). Encinas describió este y otros procesos de explotación al campesino en su tesis de derecho de 1920; el campesino, escribió, "deja la comunidad, donde es libre y propietario, por la hacienda, donde es colono y casi esclavo" (Encinas, 1920:9). Muchos indígenas de los andes sureños, ante las penurias y persecución gamonal, terminaban convirtiéndose en jornaleros de hacendados, en yanaconas de un patrón.

Simultáneamente, esta región recibía a pastores adventistas que gestionaban y ejecutaban la construcción de escuelas rurales con alcances de educación no católica para los campesinos. Los pastores adventistas, originarios de EEUU, se instalaron en Buenos Aires, donde tenían su base central en el siglo XIX, continuaron por Chile y Bolivia, luego a Puno, donde el sur altiplánico estaba conmocionado por las batallas de quechuas y aimaras (Apaza, 1948). Seguidores de la democracia y de los derechos, más liberales que los católicos, poseedores de una diferente concepción religiosa y del libre examen de la Biblia, los adventistas se mostraban inspirados por un toque de activismo político-ciudadano y un definido distanciamiento 
frente a los curas, a quienes veían como alborotadores y escolásticos, nada misioneros.

Encinas, ya como rector de la Universidad decana de América en los años 30, recordaría estos duros momentos de inicios del siglo XX, cuando dirigió una educación laica para niños de primaria, de esta manera «el laicismo en el Perú es una consecuencia lógica y una sanción para la iglesia que, en cuatro siglos de hegemonía, no ha podido redimir al indio de la ignorancia y de la esclavitud en que vive» (1958: 40). Este pedagogo optó por anular el sermón y las oraciones en la escuela, se inclinó por la libertad en el niño andino, sin adoctrinamientos. Para formar la moral de sus estudiantes, pensó en los cursos de literatura, historia, en la disciplina, el deporte, el trabajo colaborativo (Encinas, 1958).

Llegaron muchos pastores protestantes, metodistas, adventistas; Ferdinand Stahl, el más reconocido. Uno de los pastores, John MacKay, se convirtió en maestro y director en la Escuela Normal de Varones en Lima, creada por el gobierno de Pardo y Barreda; ahí se dedicó a modernizar la formación de pedagogos, incentivando la investigación, la democracia, la ciencia, la psicología, el arte, la biblioteca. Señaló, sobre Puno, que una real evangelización cristiana no se había visto en el altiplano, que en cambio los adventistas sí la expresaban (Fonseca, 1978). He ahí una incisiva crítica a la labor de los católicos, tanto a feligreses como al clero secular. Muchos puneños estudiaron en ese centro de pedagogía, Catacora y Encinas, por ejemplo.

Los adventistas traían ideas nuevas, religiosas, pero de tinte examinador, cuestionador de versiones católicas oligárquicas y ajenos al poder de gamonales y caciques regionales. En ese clima de crítica al poder local se movieron algunos puneńos con un profundo interés en relacionar esa visión política con la educación y en reclamar una legislación de respaldo social a los indígenas. Este acontecimiento, a finales del siglo XIX y mucho antes de las experiencias cusqueña y limeńa, amerita la denominación de indigenismo temprano; es decir, un movimiento intelectual, de apertura democrática, con proyecciones de vida ciudadana, pensada para los campesinos en un contexto adverso, regional y surandino. Indigenismo jurídico, le han llamado otros, por la pretensión de emitir leyes nuevas y tutelares para la población andina, «una aproximación semejantemente jurídica caracteriza a
Encinas» (Jancsó, 2009: 95). Los abogados y escritores puneños han revitalizado las acciones históricas de sus ancestros; así, uno de ellos, Augusto Ramos Zambrano ha recogido pacientemente volantes, memoriales, cartas de la época, testigos mudos de un «indigenismo de combate, de lucha abierta y decidida, de un coraje que no se dio en otras latitudes de nuestro país» (2016: 37).

La población puneña estaba ávida de soberanía popular, manifestaba una crítica ardiente contra la opresión, «los indigenistas puneños pasaron a la movilización indígena» (Liebner, 2003: 472). Viendo y sintiendo este escenario, lleno de angustia, esperanza y trabajo, un tiempo complicado para tomar serias decisiones, estaba el inquieto muchacho Encinas, que se animó a participar con sus mayores y a colaborar con ellos en una tarea de alta responsabilidad. Se convirtió, a los diecisiete años, en ayudante de Catacora en la Escuela de Perfección, donde preparaba charlas, organizaba encuentros con los jornaleros «artesanos, obreros y estudiantes» (Calsín, 2003: 61); les hablaba de la historia, informaba de los peligros del vicio del alcoholismo, analizaba con ellos la realidad nacional y mundial. Aún adolescente, buscó colaborar con los traductores de la Comisión Maguińa que investigaba los sucesos trágicos posteriores a un alzamiento campesino en su región.

Durante el gobierno del presidente López de Romaña se había dispuesto la conformación de una comisión investigadora (corría Noviembre de 1902); su misión era elaborar un informe sobre las rebeliones campesinas ocurridas, en los últimos meses, en Huanacamaya y Santa Rosa de Juli y determinar el grado de responsabilidad por las muertes durante actos violentos. El responsable de la comisión era Alejandrino Maguiña, abogado ancashino que se entrevistó con muchos indígenas de la zona y convocó a Telésforo Catacora como intérprete, un ilustrado de los andes, un indigenista de tiempos tempranos.

La Comisión había concluido, claramente, que una vía para brindar consistencia política y social a los trabajadores rurales, era la educación. El breve gobierno siguiente, a cargo de Manuel Candamo (1903-1904), dispuso que los prefectos demuestren su autonomía y actúen con decisión para frenar los terribles hechos de crímenes contra los campesinos. El joven Encinas ayudaba y observaba, atendía a los traductores, escuchaba los testimonios; forjaba así su 
carácter envuelto en emoción social, frente a una difícil experiencia. Nacía así el entusiasta en la educación, surgía el político social interesado en participar de la política en una sociedad rural.

Algunos de los indígenas conformaban comisiones o integraban grupos de mensajeros que debían realizar un pesado viaje a Lima para tramitar los pormenores de la investigación de algún luctuoso suceso, un crimen o una pérdida de tierras; aquello ocurría en el mundo andino con mucha frecuencia. Desde la infausta Guerra del Salitre, pasando por la guerra civil entre pierolistas y caceristas en marzo de 1895 y las continuas movilizaciones, Puno se quebró, para el joven Encinas, en el corazón de muchos de sus hijos (Calsín, 2003).

Los puneños Telésforo Catacora, Manuel Zuñiga Camacho, José Antonio Encinas organizaron sendos proyectos educativos para contrarrestar el problema de la tierra, para empoderar a los indígenas, para educarlos en el campo de la ciudadanía y la igualdad. Construyeron un sueño político a través de una educación en derechos, relacionando el campo educacional con la ciudadanía, con la problemática socioeconómica. Encinas estudió derecho en San Marcos y en su tesis afirma que existe la necesidad de una legislación nueva que reconozca al indio como ciudadano en pleno ejercicio de sus derechos, que esto «no surge de un concepto de inferioridad antropológica de la raza, sino de una desigualdad social» (Encinas, 1920: 7); así, el campesino tendría los instrumentos académicos y político-legales para defender su situación, para organizarse como sujeto de derecho que reconoce su carácter jurídico, estableciendo una sociedad democrática. El marco social, dentro de un esquema de modernidad y búsqueda de progreso, tendría vigencia tanto en materia económica, social, como educativa.

Poco se ha comentado, poco se ha estudiado en las aulas a estos exponentes de aquel indigenismo jurídico-educacional, como Telésforo Catacora, con su Escuela de la Perfección y también Manuel Zuñiga Camacho y su experiencia en la Escuela de Utawilaya, admirables personalidades del mundo andino sureño que sońaban con un campesinado respetado y viviendo en libertad sus derechos, ejercitados en pleno. En Puno «la corriente indigenista fue más radical y estuvo en mayor proporción relacionada con los movimientos campesinos que se suscitaron en la región desde mitades del s. XIX» (Deústua y Rénique, 1984: pp. 49-50). La oligarquía y el clero, sin pudor alguno, arremetieron contra esas aventuras pedagógicas; el uso de los poderes fácticos y los clásicos malabares jurídicos se lanzaron contra estos dos personajes de la educación rural, hombres del campo que enarbolaban un indigenismo temprano, comprometido con la doctrina educacional.

Aquella aventura terminó de mala manera, con burlas, cárcel y hasta muertos. Esos dos sufridos e incomprendidos pioneros de la educación indígena, olvidados por la dejadez oficial de la abulia administrativa vieron sabotear sus respectivos proyectos. Ya el clásico Luis E. Valcárcel, gran maestro de la etnohistoria, testigo vital de aquellos tiempos, cuenta que los diferentes movimientos indigenistas del altiplano fueron intensos, pero no visualizados como los que aparecieron en Cusco y en Lima; de Puno, dijo «ellos nos antecedieron en cuanto a actitudes francamente rebeldes» (Valcárcel, 1980: 248).

Este escenario, entonces, estaba cargado de indigenismo temprano, radical y educacional; ahí lo novedoso. Simultáneamente, hay que reconocerlo, se rodeaba de una atmósfera cristiana evangélica, renovadora y con bríos de educación rural, cuestionadora del monopolio católico, de un viento cristiano primitivo, opositor al catolicismo conservador y que soplaba contra los gamonales. Emilio Romero, quien fue uno de los niños estudiantes en el centro escolar 881, dirigido por Encinas, ha contado que el maestro se alarmó de la represión contra las escuelas adventistas, pues «los sacerdotes preocupados por la poca concurrencia católica, azuzaron a la población... para expulsar a los norteamericanos" (Tord, 1978: 186187). Hubo hostigamiento, maltrato y atropellos políticos.

Encinas creció en ese espacio, en esa atmósfera de pugnas entre iglesias, de guerras por la tierra, por el corazón y la mente de la población. Aprendió de los adventistas, de los indigenistas, de la movilización campesina. Leyó a Rousseau, Dewey gracias a la dirección de Isidoro Poiry y de J.A. Mac Night en la Escuela Normal de Varones de Lima. Siguió a Catacora y a Zuñiga Camacho, quienes tenían contacto con los estudiantes arequipeños, así con el Partido Liberal y de estos con el líder de los anarquistas, Manuel Gonzales Prada (Calsín, 2003). 
Catacora muere muy joven. Zuñiga Camacho fue agredido. Encinas toma la posta en la aventura política educacional, vuelca su vida y su trabajo hacia los niños indígenas y los hijos de los artesanos; rápidamente a los veintiún años y, con un bigotillo para sentirse mayor, asume la dirección, desde 1907 hasta 1911, del Centro Escolar No 881 en un local húmedo y pantanoso. Más tarde se muda a unos pasos de la plaza principal de Puno, donde crea, diseña y practica una educación moderna, laica, laborista, rica en ciudadanía.

El rechazo a los poderosos de la milicia, del foro y del confesionario era impactante, un escenario de clamor popular contra el despojo de tierras que sufrían los campesinos. Es por eso que el proyecto educativo de Encinas, si bien contenía elementos pedagógicos, no se cerraba en ese campo, reclamó la tierra, ya que «...los intereses económicos, constituyen el nervio de la solución del problema de la raza» (Encinas, 1920:5). Por ello, Encinas, al beber de esta fuente socio-política, germinó una corriente de pensamiento potente con alcance nacional e internacional; lástima, sin respaldo de las autoridades locales.

Es interesante la fusión muy moderna, para la región y para la época, de antropología y pedagogía que hizo este maestro provinciano (Giesecke, 2016) y que ejercía en su centro escolar. Realizó entrevistas a reos indígenas, enseñó el respeto a la mujer y promovía el régimen de escolaridad mixta en co-educación. Alimentó la facultad del niño a ser autónomo y libre de opinión. Estas ideas las tomó de la observación participante, el clásico método de la antropología. Sus niños, en su escuela, pensaban y actuaban en democracia; sus pupilos hacían caminatas, visitaban a las nińas de otro centro escolar (aunque las monjas de aquel se espantaban al ver varones cerca).

Implementó nuevas prácticas en la docencia, "hizo experimentos educativos en Puno creando una escuela nueva» (Tord, 1978:193), toda una revolución del aprender y de la metodología del estudio social. Encinas asumió la corriente pedagógica de la Escuela Nueva (activismo y racionalismo, libertad y trabajo manual). Se contagió de las influencias de los educadores europeos que llegaban al Perú con su maleta llena de modernidad educacional y política, con un cargamento de liberalismo y racionalismo. Creció influenciado por los librepensadores del altiplano. Encinas recoge esta ola ilustrada y la acrecienta.
En su legendaria escuela, incentivó las asambleas de estudiantes como medio democrático para forjar ciudadanos. Había cursos de jardinería, carpintería, se aprendía en teoría y en la práctica. Las matemáticas debían tener aplicación en la vida cotidiana, no abstracciones. El dibujo, el arte, el deporte y la caminata por el campo, acompańaban perfectamente sus clases. Los maestros debían estar capacitados, entrenados en sicología del niño, ser especialistas de una asignatura para dedicarse de lleno a la investigación junto a los niños. No aceptaba que el profesor dedique largas horas ante los estudiantes, dirigiendo varios cursos.

Al nińo se le otorgaba libertad de acción, a más libertad, decía, más disciplina. Entendía la disciplina como ordenamiento de trabajo en conjunto, armonía entre compañeros de labor, no la tiranía o el castigo autoritario de un cuartel, donde hay subordinados y mandones. No rezaban, ni comentaban de doctrinas religiosas, pues lo consideraba fantasioso y abstracto para la tierna inocencia de un infante. El maestro no era un adoctrinador, un publicista, era un guía de la reflexión en conjunto.

Casi de inmediato, también, es hostilizado por las autoridades seńoriales y, más tarde, terminó desterrado. Fue la presión de seres oscuros, grupos de poder económico, político e ideológico, que de tanto adorar el oro y la espada, no miraron a los ojos de los niños indígenas.

\section{Conclusiones}

Los pioneros de un indigenismo temprano, como Catacora y Zuñiga y sus respectivas escuelas rurales, sirvieron de modelo al adolescente Encinas para dedicarse a la docencia de niños rurales. Su apego al comunero, al jornalero, al artesano, a través de jornadas académicas populares se implementó en Puno, mucho antes de acciones semejantes de Cusco y Lima (como las universidades populares Manuel González Prada).

La niñez y adolescencia de Encinas estuvo marcada por las rebeliones campesinas de diferentes distritos y pueblos de Puno a fines del siglo XIX e inicios del siglo $\mathrm{XX}$, sucesos trágicos que evidenciaban la debilidad jurídica, económica y política de los trabajadores agrícolas. La desigualdad social era 
tremenda, los puneños como Catacora, Camacho y Encinas se organizaron para remediar esto. Sabían que se necesitaba cambiar en muchos campos; ellos asumieron, con gran tesón, la transformación en el camino educativo.

José Antonio Encinas elaboró y llevó a la práctica un proyecto educativo innovador basado en la reflexión de los cursos, en la discusión de la historia, revisando la psicología de los personajes de la literatura, sembrando el jardín para conocer ciencias naturales, practicando deporte, escalando montañas. Era la modernidad en el aprendizaje, la libertad de pensamiento, acción y laboriosidad en la comunidad, así como la defensa de los pobladores rurales contra los abusos del clero y de los gamonales.

Los inmigrantes adventistas ejercieron influencia en la vida y la pedagogía de estos maestros puneños; con sus escuelas y centros de salud, con sus críticas al poder católico, su interés en la alfabetización del campesino; es decir, esta formación de ciudadanía sirvió de acicate a los indigenistas de una época temprana, de una zona cercana a las estrellas, pero lejana a los derechos de todo ser humano.

\section{Bibliografía}

Apaza, P. (1948). Los adventistas y la educación del indio en Puno. Tesis de licenciatura en educación. Lima: UNMSM, Facultad de Educación.

BASADre, J. (2005). La vida y la historia. Lima: El Comercio Biblioteca Nacional (BN). (1899-1905). Manuscritos de prefectos y sub-prefectos de Puno (Colección Zegarra).

Burga, M. \& Flores Galindo, A. (1979). Apogeo y crisis de la República aristocrática. Lima: Editorial Rikchay.

Burga, M. \& ReÁtegui, W. (1981). Lanas y capital mercantil. $1^{\circ}$ ed. Lima: Instituto de Estudios Peruanos.

Bustamante, J. (1959). Viaje al antiguo Mundo. Lima: Munilibros.

Ccahunan, J. (2013). Según la capacidad intelectual de cada uno: élites, Estado y educación indigena a inicios del siglo XX. (Tesis de pre-grado). Lima, PUCP (Consultado el 04 de mayo de 2018). Disponible en http://tesis.pucp.edu.pe/repositorio/bitstream/handle/123456789/5126/CCAHUANA_ CORDOVA_JORGE_CAPACIDAD_INDIGENA. pdf? sequence $=1 \&$ isAllowed $=y$
Calsín, R. (2003). Escuela de perfección. Juliaca: René impresores.

Deústua, José y Rénique, José Luis (1984). Intelectuales, indigenismo y descentralismo en el Perú, 1897-1931. Cusco, Perú: CBC

El Comercio (1903). tomo I y II. Lima, Biblioteca Nacional.

Encinas, J. A. (1913). La educación su función social en el Perú (tesis de Bachiller en Letras). Lima: Universidad Nacional Mayor de San Marcos.

Encinas, J. A. (1917). Causas de la criminalidad indigena (tesis en Derecho). Lima: Universidad Nacional Mayor de San Marcos.

Encinas, J. A. (1920). Contribución a una Legislación Tutelar del indígena. Lima: Editorial Villarán.

Encinas, J. A. (1958). Ensayo de Escuela Nueva. Lima: Munilibros.

Escarrachi, M. (1966). Doctrina educacional de José Antonio Encinas. (Tesis de Licenciatura en Educación), Lima: Universidad Nacional Mayor de San Marcos.

Espinoza, G. A. (2007). Libros escolares y educación primaria en la ciudad de Lima durante el siglo XIX. (Consultado el 22 de octubre de 2017). Disponible en http://revistas.pucp.edu.pe/index.php/historica/article/view/234

Flores Barboza, J. (2007). A cien años de la iniciación de Encinas. Revista de Investigación. Vol. 11 ( $\left.\mathrm{N}^{\circ} 19\right)$, (Consultado el 04 de Octubre de 2015). Disponible en http://sisbib.unmsm.edu.pe/bibvirtualdata/publicaciones/inv_educativa/2007_n19/a13.pdf

Fonseca, J., 2002 - Misiones y civilizadores: Protestantismo y modernización en el Perú 1915-1930, Lima: Pontificia Universidad Católica del Perú.

Giesecke, M., 2016 - Escuela Nueva y Antropología Aplicada, educación rural en el Perú en las décadas de 1920 y 1930, en Revista Anthropologica 34 (36): 31-52, Lima: Pontificia Universidad Católica del Per

Giusti, M., 2015- Entrevista. Lima (consultado el 12 de julio de 2016). Recuperado de https://redaccion. lamula.pe/2015/07/22/miguel-giusti-mientras-masintolerantes-somos-menos-derechos-se-reconocen/ rlescanomendez/

GonZales, O., 2013- Nueva Escuela para una nueva nación, 1919-1932. Lima: Derrama Magisterial

Jacobsen, N., 2013 - Ilusiones de la Transición. El Altiplano peruano, 1780-1930. Lima: Instituto de Estudios Peruanos

Jancsó, K. 2009- Indigenismo Político Temprano en el Perú y la Asociación Pro-Indígena. Tesis doctoral. (Consultado 
el 18 de octubre de 2013). Disponible en https://www. researchgate.net/publication/278505584_El_indigenismo_politico_temprano_y_la_Asociacion_ProIndigena

López Martínez, H., 1973 - José Antonio Encinas y la Reforma Universitaria. En El Comercio 16 de setiembre, pág. 24

Leibner, Gerardo. 2017- La Protesta y la andinización del anarquismo en el Perú 1912-1915. (Consultado el 20 de noviembre de 2017). Disponible en http://eial.tau. ac.il/index.php/eial/article/view/1228/1256

Marrou, A. 2003- José Antonio Encinas Franco. Revista de investigación, Vol. 7 ,

$\mathrm{N}^{\circ}$ 12. (Consultado el 22 de Mayo de 2013). Disponible en http://www.une.edu.pe/investigacion/TIPS/4.Jose $\% 20$ Antonio\%20Encinas.pdf

Martínez, F. (1998). Los primeros pasos liberales hacia la unificación escolar en Bolivia. (Consultado el 10 de noviembre de 2017). Disponible en https:// www.researchgate.net/publication/47461914_Los_ primeros_pasos_liberales_hacia_la_unificacion_ escolar_en_Bolivia

Pareja Paz Soldán, José - 1978- José Antonio Encinas. En Suplemento La Imagen, La Prensa, Lima, 29 de octubre, pág. 19

Portugal Catacora, J., 1988 - José Antonio Encinas, el maestro de los maestros peruanos, Lima: Concytec

Ramos Zambrano, A., 2016- Ezequiel Urviola y el indigenismo puneño. Lima: Fondo editorial del Congreso de la República

SÁnchez, D., 2004 - Encinas, maestro del Perú profundo. Lima: Derrama magisterial

STERN, S., 1990 - Resistencia, rebelión y consciencia campesina en los andes, Lima: Instituto de Estudios Peruanos

Tord, L. E., 1978 - El Indio en los Ensayistas Peruanos (1848-1948), Lima: Editoriales Unidas

ValCárCel, L. E., 1980 - Memorias, Lima: Instituto de Estudios Peruanos 

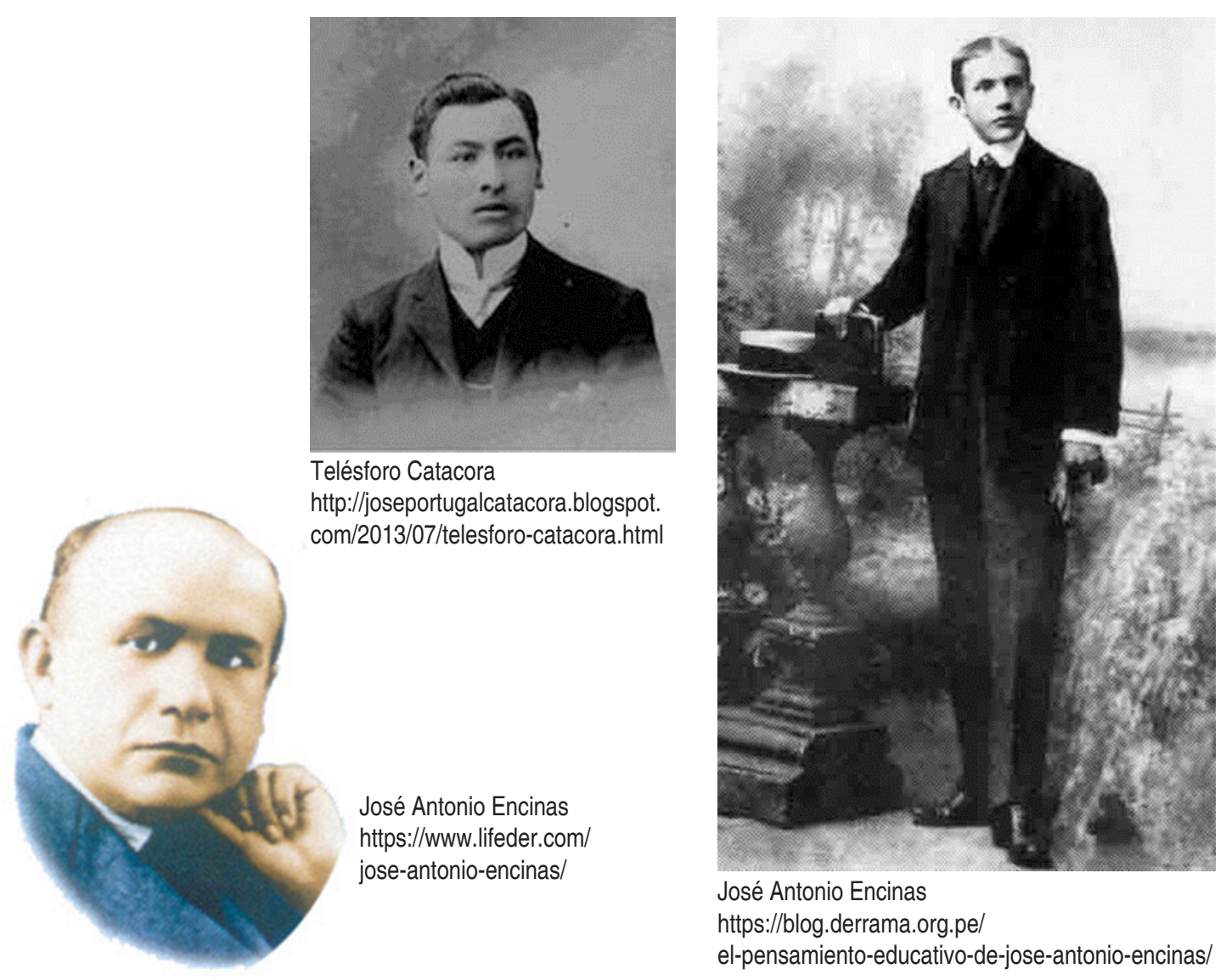

José Antonio Encinas https://www.lifeder.com/ jose-antonio-encinas/

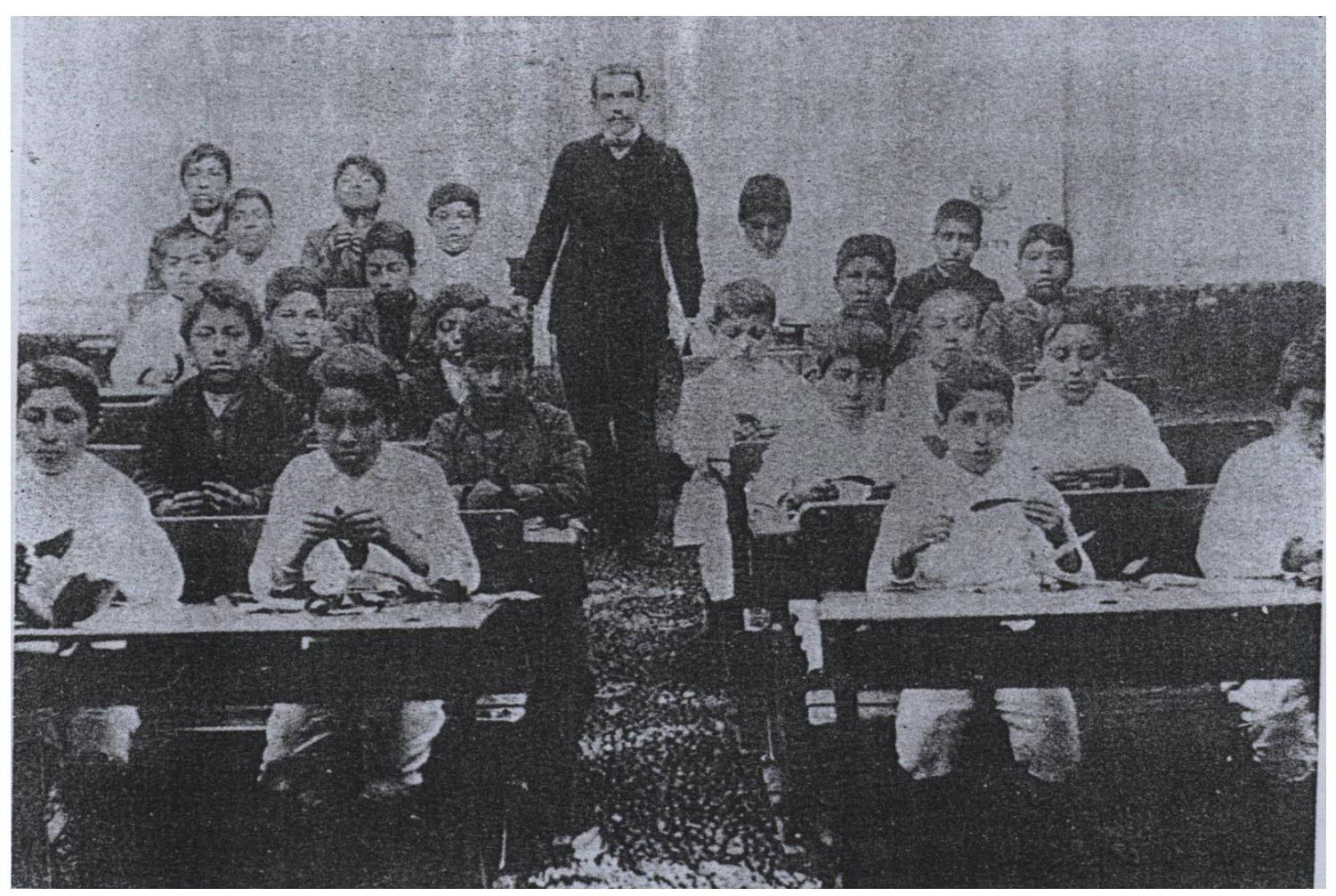

Encinas y sus estudiantes en el Centro escolar 881

http://joseportugalcatacora.blogspot.com/2011/08/el-maestro-encinas-y-jose-portugal.html 